\title{
Feingold Syndrome
}

National Cancer Institute

\section{Source}

National Cancer Institute. Feingold Syndrome. NCI Thesaurus. Code C74987.

A rare autosomal dominant syndrome caused by mutations in the MYCN oncogene. It is characterized by microcephaly, limb abnormalities, esophageal and/or duodenal atresia. 